\title{
Asian-Americans Solidarity through We Bare Bears Series Case Study: Money Man Episode
}

\author{
Alfi Zulfa Nooraida ${ }^{1}$, Meidia Rea Smithiana ${ }^{2}$ \\ \{alfi.zulfa@ui.ac.id ${ }^{1}$, meidia.rea@ui.ac.id ${ }^{2}$ \} \\ ${ }^{1,2}$ Universitas Indonesia, Jakarta, Indonesia
}

\begin{abstract}
Since We Bare Bears Series was released in 2014, it has not been analysed by academicians especially on Money Man episode. In Money Man episode of We Bare Bears Series tells about life of Asians-Americans. The purpose of research is to analyze the message in the Money Man episode of We Bare Bear series. The research collaborates the close reading method, focusing on the characterization, identifying the plot and elaborates the recent research findings for collective action Asians-Americans. The findings show the competition process between two Asians-Americans, occurs when Chloe Park and Saanvi Patel were competing each other to get the grants from Dr Bean, the symbolism disappearance of grantor as the event of economic changes, and the solidarity were made. This episode has different opinion from findings of the recent research which stated the economic and demographic changes predicted to intergroup competition between Asians and Non-Asians has no effects on the rate of pan-Asian collective action. The message of the Money Man episode shows that Asian-Americans seemed to compete each other, but as minorities they would actually unite to survive in the area where minorities repressed because of the White Supremacy rhetoric that still presents around their environments.
\end{abstract}

Keywords: Asian-American, competition, solidarity, we bare bears

\section{INTRODUCTION}

The recent research about Asian-Americans collective action, the occupational segregation generates pan-ethnic group especially Asian-Americans through the intergroup interaction, common economic interest, and membership in a community of faith. And the results also revealed that intragroup competition process decreasing the collective action based on pannational boundary. But economic and demographic changes predicted to intergroup competition between Asians and Non-Asians has no effects on the rate of pan-Asian collective action. [1]

America has been multicultural. Since 1950 and after the changes in immigration law in 1965, people from various ethnic grown at an astounding rate. The numbers of people from over 100 countries boast significantly at United States. This was caused by the changes in immigration system, which previously based on quota per countries changed into reunification of families and priority for high-skilled labours. In the first five years, immigrants from Asian 
countries, especially those who flee from the Southeast Asia wars such as Vietnam and Cambodia, came in huge amounts to the U.S [2]

One of the works that bring the multiculturalism issue in America is We Bare Bears. We Bare Bears is an animated sitcom series, premiered at Cartoon Network in 2014. Cartoon Network is known as American pay television channel and primarily broadcast animated television series. It operates from 6.00 AM to 8 PM made it targeted for children between 7-15 years old [3]. We Bare Bears series created by Daniel Chong, a Singaporean-American who previously worked as story artist for Pixar Animation Studios, Nickelodeon, Blue Sky, and Illumination Entertainment[4]. The idea of the making We Bare Bears was from the creator saw some people treated bears unfairly like the experience of the creator, just because of his different appearance as Asian-American[5]. We Bare Bear tells the life story of three different species of bears bonded by brotherhood. The Bears lived like humans and lived in harmony with humans although they still claimed themselves as bear. The Bears are Grizz: the grizzly bear, Panda: the panda bear and Ice Bear: the polar bear. We Bare Bears can be a modern multiculturalism narrative because according to the creator, it makes an allegory for how it feels to become a minority among multicultural living of America [5]. One of the We Bare Bear episodes that told Asian-Americans as the main character is "Money Man" episode. In This episode the two main characters of Asian-Americans are Chloe Park and Saanvi Patel. Since it was released in 2014, We Bare Bears Series has not been analysed by academicians especially on Money Man episode.

\section{METHOD}

This paper will analyze the messages of Money Man episode portraying the life of AsianAmericans in America. Despite all the multicultural values on the We Bear Bears, the relationship between Chloe Park and Saanvi Patel is the main issue of one of this serial's episode. In this episode, the relationship between them are intriguing, since both girls are Asians with different ethnicities. The research collaborates the close reading method, focusing on the characterisation, identifying the plot and elaborate the recent research findings for collective action Asians-Americans. After that, the authors will identify the messages about Asian descents' situation in America.

\section{RESULT AND DISCUSSION}

In the first minutes of the episode we can see that Chloe has already been the friends with the Bears. Chloe lead the Bears to help her in the science competition. The Bears actually were the main characters on We Bare Bears Series. We can see The Bears on every episode of We Bare Bears series. The Bears lived like humans and they still claimed themselves as bears. This means The Bears were characters of minorities since they were Bear not humans. Chloe Park is the side character that appeared on We Bare Bears series. But in the Money Man episode, Chloe became the main character. Chloe Park was a twelve year-old KoreanAmerican girl, who skipped Junior High School to University made her known as a prodigy. Chloe was currently studying at the University of California. Chloe was the first human character that entered the cave, the home of the Bears. Character of Chloe portrayed as an Asian-American in human form and representing the creator of We Bare Bears, Daniel Chong who is Asian-American as well. And Chloe Park was made by Bert Youn, a board artist from Korea [6]. 
Another character that became the main focus in this research was Saanvi Patel. Saanvi Patel was presumably an Indian-American. The name Saanvi refers to Lakshmi, the goddess in the Hindu culture [7]. Other than that, can be seen as her dark complexion and black hair tied into a bun. This character portrayed as an antagonist character, because she appeared to bully Chloe Park. Saanvi Patel was also described as a smart girl because of her ability to create navigation machine to find lost items. However, both Chloe and Saanvi had characteristics in common. They were college student, ace in science and compete to be the best. Both of them were Asians-Americans. It means they had similar pan-ethnics and they have similar work experiences, similar structural position. They competed each other and strived to be the best. In this process, there were two different ethnics appeared, although they came from the similar pan-ethnics and competed each other.

On the other hand, Dr Bean was portrayed as a grey-haired old man with grey suit and yellow tie. Dr Bean was the only judge presented for this science competition. Chloe described him as a donator all the funding for the college building. The name of this episode called Money Man. The term "Money Man" can be referred as financier [8] or someone who handle the money [9]. From that term, Dr Bean can be referred as the money man. Chloe and Saanvi were both competing for the prizes from Dr Bean. It means they both competing for the same resources. While in the judging process, Chloe and Saanvi still persuaded Dr Bean to choose one of them to be the winner. However, this 'persuasion moment' or a time to win Dr Bean's heart turned out into fight between these girls.

Frankly said, Dr Bean thought both Chloe and Saanvi had amazing inventions. He said "who? I can't decide," when Chloe and Saanvi were fighting about who were supposed to be the winner. Therefore, he could not decide who was going to be the winner until he disappeared somewhere. He decided to leave them because Chloe and Saanvi were fighting each other. The disappearance of Dr Bean means that the resources was gone, since he was the one who had the money. The disappearance of resource made the uncertainty of who would be the winner. The disappearance of resource can be symbolized as economic changes.

Both Chloe and Saanvi were confidence; they thought they were potential and had the same chances to be a winner. However, Chloe and Saanvi eventually found out that Dr Bean actually did compliment all of the contestants. It was shown by the lines between student A and student $\mathrm{B}$ below.

Student A: Huh? What did Dr Bean say?

Student B: He said it was the best thing he's seen, and then he disappeared.

Student A: Said the same thing to me!

(07:54-07:59)

Thus, Chloe offered Saanvi to collaborate in making their machines. At first, Saanvi refused the offer. She changed her mind later and decided to accept the offer. In this scene, it displayed how Chloe, Saanvi and their teams worked together. It seemed that they became very cooperative and did not fight during the collaboration. In this situation, it indicates that the economic changes made the collaboration of both Asian-Americans to get the resource back. Therefore, this proved the contrasted result compared to the recent research, since it stated economic and demographic changes predicted to intergroup competition between Asians and Non-Asians has no effects on the rate of pan-Asian collective action [1].

Fast forward to the next scene, they found out Dr Bean and he had already chosen the winner. The winner was the Jock Guy. The Jock Guy was portrayed as a tall, blond-haired, had white complexion and wore a red sport jacket. Based on his appearance, the Jock Guy identified as a White (Caucasian). He appeared at the beginning of this episode, when he was interrupting Chloe and Saanvi's fight. Initially, the term 'Jock' was an abbreviation of jockey, 
which means 'the rider of horse races in late $18^{\text {th }}$ century' $[10]$. On the other hand, in the American popular culture, the term 'Jock' is known for 'college athlete or someone who is extremely enthusiast about sports'[11]. They often called as musclehead, meathead, or musclebrain, which means they are muscular, and very smart at sports [12]. Usually, Jock are often compared with the Nerds who are identified smart at science, in terms of achievements. Therefore, from that scene, we found out that Dr Bean chose the person without proper reasoning, since Jock's invention was only a 'smiling ball'. The 'smiling ball' was obviously less sophisticated than Chloe and Saanvi's machine. Thus, this decision led confusion to Chloe and Saanvi. Dr Bean's choice to make Jock as a winner might be caused by three possibilities: whether because Jock was a male, he was a white, or both (a white male). Since White people dominating United States, so White people have more privilege and White Supremacy ideology was formed [13] [14][15] .

Lastly at the ending scene, although Chloe and Saanvi did not win, they seemed to solve their grudge towards each other and decided that they were not going to fight anymore. At the end of the day, they complimented each other about their amazing works. They thought their invention would change the world, too. Nonetheless, before they could actualize their dreams, their machine surprisingly was taken by the government's representatives. They say, "this is government's property now, move aside!" There, Chloe and Saanvi just left dumbfounded and did not actually do anything, such as preventing their machine taken by the representatives. This scene could tell the audiences that Asian-Americans were often belittled in some aspects of daily lives. Here, Chloe and Saanvi's inventions would probably be published by the government anonymously, without giving any credits to them. Since the Cartoon Network targeted for children between 7-15 years old, the Money Man episode give the understanding for children that Asian-Americans as a minorities they would actually unite to survive in the area where minorities repressed because of the White Supremacy rhetoric that still presents around their environments [16].

\section{CONCLUSION}

In this paper, the author looked competition event among two different Asian-Americans based on the plot in the "Money Man" episode of "We Bare Bears" series. From the perspective of Money Man episode, the collective action of Asian-Americans begun from economic changes in the intergroup competition. The competition process between two Asians-Americans, occurs when Chloe Park and Saanvi Patel were competing each other to get the grants from Dr Bean, the symbolism disappearance of grantor as the event of economic changes, and the solidarity were made. The analysis of the Money Man episode has conflicting opinions compared to the findings of the recent researches which stated that the economic and demographic changes predicted to intergroup competition between Asians and Non-Asians have no effects on the rate of pan-Asian collective action. The message of the Money Man episode also gives the understanding for children that although Asian-Americans are still considered as a minority group especially in the U.S., they would actually unite to survive in the area where minorities are often repressed and confronted because of the White Supremacy rhetoric which still presents around their environments.

\section{REFERENCE}

[1] D. G. Okamoto, "Toward a Theory of Panethnicity: Explaining Asian American Collective Action,” Am. Sociol. Rev., vol. 68, no. 6, pp. 811-842, 2003.

[2] History, "U.S. Immigration Since 1965 - HISTORY," A\&E Television Networks, 2010. 
[Online]. Available: https://www.history.com/topics/immigration/us-immigration-since1965. [Accessed: 14-Apr-2019].

[3] ICv2, "ICv2: Adult Swim/CN Split Cements Strategy," 2005. [Online]. Available: https://icv2.com/articles/comics/view/6516/adult-swim-cn-split-cements-strategy. [Accessed: 05-May-2019].

[4] "Daniel Chong - IMDb." [Online]. Available: https://www.imdb.com/name/nm5512802/. [Accessed: 17-Mar-2019].

[5] D. Chong, "Daniel Chong on Twitter: \&quot;Why I created WE BARE BEARS.... \&quot;", 2016. [Online]. Available: https://twitter.com/threebarebears/status/797119393557659648. [Accessed: 13-Mar2019].

[6] A. de Souza, "Multicultural characters abound in We Bare Bears, Lifestyle News \&amp; Top Stories - The Straits Times," 2017. [Online]. Available: https://www.straitstimes.com/lifestyle/multicultural-characters-abound-in-we-bare-bears. [Accessed: 13-Mar-2019].

[7] "Saanvi - Meaning of Saanvi | Hindu Name Saanvi | Bachpan.com." [Online]. Available: https://www.bachpan.com/Meaning-of-Saanvi.aspx. [Accessed: 03-Apr-2019].

[8] Merriam Webster, "Moneyman | Definition of Moneyman by Merriam-Webster," 1828. [Online]. Available: https://www.merriam-webster.com/dictionary/moneyman. [Accessed: 17-Mar-2019].

[9] "Moneyman definition and meaning / Collins English Dictionary." [Online]. Available: https://www.collinsdictionary.com/dictionary/english/moneyman. [Accessed: 17-Mar2019].

[10] “jock | Definition of jock in US English by Oxford Dictionaries." [Online]. Available: https://en.oxforddictionaries.com/definition/us/jock\#jock-2. [Accessed: 18-Mar-2019].

[11] "Jock | Definition of Jock by Merriam-Webster." [Online]. Available: https://www.merriam-webster.com/dictionary/jock. [Accessed: 18-Mar-2019].

[12] "Jock as Youth Subculture," Center for Mental Health in Schools. [Online]. Available: smhp.psych.ucla.edu/pdfdocs/youth/jocks.pdf. [Accessed: 19-Mar-2019].

[13] V. B. Treitler, "Social Agency and White Supremacy in Immigration Studies," Sociol. Race Ethn., vol. 1, no. 1, pp. 153-165, 2015.

[14] L. Pulido, "Geographies of race and ethnicity 1: White supremacy vs white privilege in environmental racism research," Prog. Hum. Geogr., vol. 39, no. 6, pp. 809-817, 2015.

[15] A. J. I. Bonds, "Beyond white privilege: Geographies of white supremacy and settler colonialism," Prog. Hum. Geogr., vol. 40, no. 6, pp. 715-733, 2016.

[16] K. Saddhono, "Cultural and social change of foreign students in Indonesia: The influence of Javanese Culture in Teaching Indonesian to Speakers of Other Languages (TISOL)." IOP Conf. Ser.: Ear. and Envi. Sci.. vol. 126 no. 1 IOP Publishing, 2018. 